\title{
PAPERS
}

\section{Systemic and local immune responses against Helicobacter pylori urease in patients with chronic gastritis: distinct IgA and IgG productive sites}

\author{
S Futagami, H Takahashi, Y Norose, M Kobayashi
}

\begin{abstract}
Background-Helicobacter pylori urease is a major target for immune responses among various bacterial components in $H$ pylori infected patients.

Aims-To analyse the relation between systemic and local humoral immune responses to $H$ pylori urease and grades of chronic gastritis.

Patients-Seventy five patients with chronic gastritis associated with $H$ pylori infection were classified into three groups (grade I, superficial gastritis; II, atrophic gastritis, quiescent; or III, atrophic gastritis, active).

Methods-Anti-H pylori urease specific antibodies in the serum, gastric juice, and biopsy specimens were determined by ELISA or western blotting analysis. The sites for $H$ pylori urease and its specific antibody producing $B$ lymphocytes were confirmed by immunohistochemical analysis.

Results-In the sera of patients with grade I gastritis, weak IgG but relatively strong IgA responses to $H$ pylori urease were observed; dominant strong IgG responses were detected in grade II gastritis. In grade III gastritis, significant IgG and IgA responses were obtained. A similar pattern of IgA and IgG responses was detected in gastric juice and tissue. $H$ pylori urease specific, antibody producing $B$ cells were not found in the gastric mucosa of patients with grade I gastritis despite the presence of such $B$ cells in the duodenal bulb. Specific $B$ cells were observed in the gastric mucosa of patients with grade II and III gastritis with atrophy.

Conclusions-Purified $H$ pylori urease, together with localisation of its specific antibody producing $B$ cells, are useful for serological testing and histopathological analysis for determining the stage of chronic gastritis and studying the pathogenesis of $H$ pylori infection.

(Gut 1998;43:168-175)
\end{abstract}

Keywords: Helicobacter pylori; urease; chronic gastritis; B lymphocytes; antibody production; local immunity
Helicobacter pylori infection of the stomach is the major cause of type B gastritis, ${ }^{12}$ and colonisation of the gastric epithelium by $H$ pylori will lead to a chronic inflammatory reaction..$^{3-5}$ Such a reaction may involve specific IgG and/or IgA antibody responses against the bacteria in the peripheral blood as well as in the gastric mucosa. However, despite the production of such antibodies, the microorganism usually persists and gastritis progresses chronically through unknown mechanisms.

We have previously reported that $H$ pylori urease, in particular its B subunit (large subunit), is a major target for immune responses in patients with various gastroduodenal diseases. ${ }^{6}$ Similar observations have been made by several other groups. ${ }^{7-9}$ In a previous report, we also showed that IgG responses to the commercially available whole $H$ pylori lysate, representing a mixture of several different strains which may react with various antibodies, varied among patients with chronic gastritis. Also, it has been shown that some $H$ pylori derived antigens are shared with other bacteria, such as Campylobacter jejuni. ${ }^{7}$ Therefore, to understand further $H$ pylori associated gastritis, it may be worth investigating such humoral immune responses to more purified antigenic protein(s) such as $H$ pylori urease, a highly potent target antigen for immunological responses among the various $H$ pylori components, ${ }^{6-9}$ and essential for colonisation of the gastric mucosa by the bacteria. ${ }^{1011}$

To analyse and assess the relation between systemic and local humoral immune responses to $H$ pylori urease and the degree of $H$ pylori associated chronic gastritis, we classified chronic gastritis into three grades (I, II, III) based on the recently established histopathological classification, the Sydney system. ${ }^{12} 13$

In the present study we investigated the antibody responses to purified $H$ pylori urease and the localisation of specific antibody producing B cells according to immunoglobulin subtype and grade of gastritis. We will discuss the importance of such serological testing and histopathological analysis in determining the actual type and stage of $H$ pylori associated chronic gastritis.
Accepted for publication 18 February 1998 
Table 1 Characteristics of $H$ pylori infected patient groups and histopathological grading according to the Sydney system

\begin{tabular}{lll}
\hline $\begin{array}{l}\text { Classification of } \\
\text { gastritis }\end{array}$ & Number of patients * & Average age (y) \\
\hline Grade I & $25(7)$ & 26.3 \\
Grade II & $25(14)$ & 46.9 \\
Grade III & $25(17)$ & 45.8 \\
Disease controls & $25(12)$ & 44.1 \\
Healthy controls & $25(12)$ & 20.3 \\
\hline
\end{tabular}

^Numbers in parentheses are men.

\section{Methods}

PATIENTS

Patients were tested by diagnostic upper gastrointestinal endoscopy for dyspeptic symptoms at the Digestive Endoscopic Centre of Nippon Medical School. A total of 75 patients with chronic gastritis who had a positive rapid urease test (CLOtest) ${ }^{14}$ and/or histological identification of $H$ pylori, was selected as $H$ pylori infected cases. Disease controls were 25 patients with drug induced gastritis due to long term use of non-steroidal anti-inflammatory drugs (such as aspirin and diclofenac sodium); an equal number of healthy volunteers (medical students from Nippon Medical School) with a mean age of around 20 years were selected as healthy controls. The disease control group was confirmed as $H$ pylori negative with a negative CLOtest, urea breath test (UBT), ${ }^{15}$ and negative histology; the healthy control group was negative by UBT. Table 1 summarises the sex and age distribution of the various groups. The protocol was approved by the Ethical Review Committee of Nippon Medical School Hospital, and all patients gave written informed consent at the beginning of the study.

CLOtest AND HISTOLOGICAL EXAMINATION

Six antral and three corpus biopsy specimens were obtained from every patient at the time of gastroscopy. One antral and one gastric body specimen were used for the CLOtest (Delta West, Bentley, Australia). Two antral and two corpus biopsy specimens were submitted for histological examination. The remaining three antral specimens were used as a source of local tissue proteins. The samples of duodenum for immunohistochemistry were obtained from the duodenal bulb. $H$ pylori associated gastritis was determined by either the presence of $\mathrm{H}$ pylor $i$ in histological specimens, a positive CLOtest, or both. The presence of $H$ pylori was detected histologically using Giemsa staining. ${ }^{16}$ Biopsy specimens were stained with haematoxylin and eosin and graded for gastritis by the same experienced pathologist according to the Sydney system. ${ }^{12}{ }^{13}$ The histological variables were scored on a four point scale: 0 , absent; 1 , mild; 2 , moderate; and 3, severe. Inflammation was examined for the presence and density of mononuclear cells in the lamina propria; atrophy for the loss of gastric glands. $H$ pylori associated gastritis was classified into three groups (grade I, II, and III; 25 patients each) based on the sum of inflammation (1-3) and atrophy (1-3) scores of antral biopsy specimens as defined in the Sydney system: grade I gastri- tis was shown as score $1-2$, grade II as $3-4$, and grade III as $5-6 .{ }^{12}{ }^{13}$ As every patient with atrophy had also moderate (2) or severe (3) inflammation, grade I (1-2) corresponded precisely to superficial gastritis without atrophy as shown by Whitehead et al. ${ }^{17}$ Grades II and III corresponded closely to atrophic gastritis, quiescent $(24 / 25 ; 96 \%)$, and atrophic gastritis, active $(24 / 25 ; 96 \%)$, respectively. Other elements of scores in the Sydney system, such as intestinal metaplasia and activity, were not used to grade the gastritis.

\section{ANTIGEN (H PYLORI UREASE) PREPARATION}

The antigen ( $H$ pylori urease) used in the following enzyme linked immunosorbent assay (ELISA) test was prepared from a mixture of $H$ pylori NCTC 11637 and clinical isolates ${ }^{6}$ cultured on Skirrow plates containing 7\% (vol/ vol) defibrinated horse blood in an atmosphere consisting of $5 \% \mathrm{O}_{2}, 15 \% \mathrm{CO}_{2}$, and $80 \% \mathrm{~N}_{2}$ at $37^{\circ} \mathrm{C}$ for four to five days. A bacterial suspension was harvested by centrifugation (5000 $\mathrm{g}$ for 20 minutes at $4^{\circ} \mathrm{C}$ ), washed twice with sodium phosphate, and stored as a cell pellet at $-20^{\circ} \mathrm{C}$. The cell pellet was resuspended in distilled water, vortexed for 45 to 60 seconds, and centrifuged (10 $000 \mathrm{~g}$ for $20 \mathrm{~min}-$ utes at $4^{\circ} \mathrm{C}$ ). The supernatant was subjected to ion exchange chromatography (PRODUCTIVE Column; BPS Separation Ltd, Spennymoor, Durham, UK) by a stepwise method (0, $0.2,0.35$, and $0.5 \mathrm{~mol} / 1$ sodium phosphate buffer). The fractions showing maximum urease activity were further purified by size exclusion chromatography with a Sephacryl S-300 column (Pharmacia LKB Biotechnology, Bjorkgatan, Uppsala, Sweden) and used as a purified $H$ pylori urease antigen. The purified urease had a molecular weight of $550 \mathrm{kDa}$ and was composed of six complexes of the small subunit of $30 \mathrm{kDa}$ (UreA) and large subunit of $62 \mathrm{kDa}(\mathrm{UreB})^{18}$ as determined by the use of specific monoclonal antibodies ${ }^{19}$ on western blotting analysis (not shown).

ELISA TEST FOR H PYLORI

The purified $H$ pylori urease antigen was diluted in $0.1 \mathrm{~mol} / 1$ carbonate buffer $(\mathrm{pH} 9.6)$ to yield the optimal protein concentration of 10 $\mu \mathrm{g} / \mathrm{ml}$. A $50 \mu \mathrm{l}$ aliquot of the antigen solution was added to each well of flat bottomed Immulon 2 plates (Dynatech Laboratories Inc., Alexandria, Virginia, USA) and incubated for 60 minutes at $37^{\circ} \mathrm{C}$. After overnight blocking with 25\% Block-Ace (Dainihon Seiyaku, Osaka, Japan), a $50 \mu \mathrm{l}$ aliquot of appropriate dilution of the sample sera (sequentially diluted $1 / 10$ to $1 / 80$ ) and the positive reference serum (diluted 1/80) was plated for 60 minutes at $37^{\circ} \mathrm{C}$. After washing, a $50 \mu \mathrm{l}$ aliquot of an appropriately diluted class specific (IgA or IgG) alkaline phosphatase conjugated goat antihuman immunoglobulin (Cappel, Durham, North Carolina, USA) was added for another 60 minutes at $37^{\circ} \mathrm{C}$; the amount of alkaline phosphatase bound to the well was determined by measuring the hydrolysis of p-nitrophenyl phosphate (Sigma Chemical Co., St Louis, Missouri, USA) to the yellow 

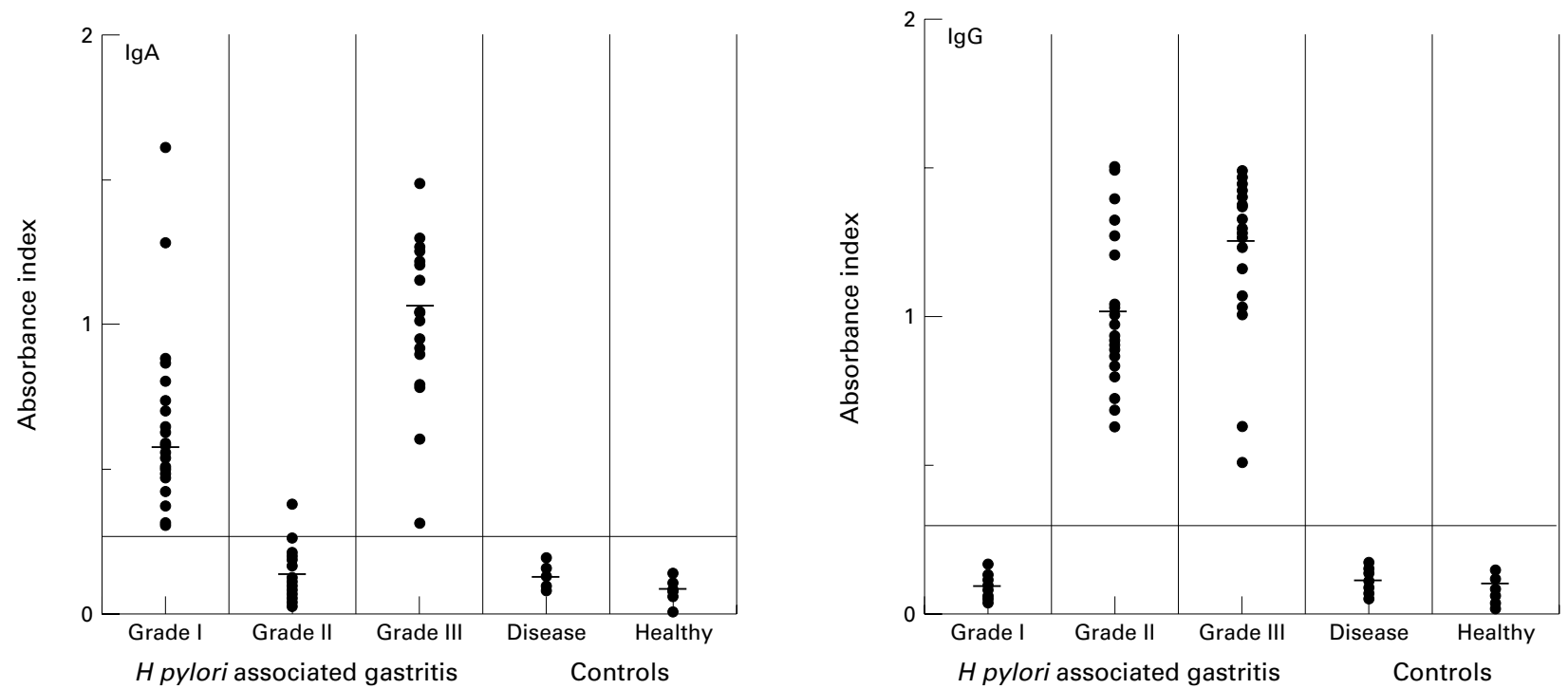

Figure 1 H pylori urease specific IgG and IgA responses in sera. Horizontal bars represent median values. Horizontal lines indicate cut off levels used in the assay.

product, $p$-nitrophenolate, which was quantitated by absorbance at $405 \mathrm{~nm}$ with a microplate reader (Model 3550; Bio-Rad, Tokyo, Japan). To standardise the ELISA, the cut off points for both IgA (0.28) and IgG (0.32) were determined using sera from 25 control patients not infected with $H$ pylori; a titre was considered positive if the optical density (OD) exceeded the mean $+3 S D$ of the control serum samples. ${ }^{20}$ Based on these cut off points, reference IgA and IgG sera were made by pooling for each reference standard, five sera positive for either IgA or IgG specific to $H$ pylori urease. The mean (SD) absorbance of the reference serum was $0.54(0.14)$ for IgA and $0.97(0.13)$ for IgG. These values were used to correct the absorbance reading when patient serum was tested. The results were expressed as the absorbance index $(\mathrm{AI})^{21-24}$ obtained using the following formula:

Absorbance index $=$ (mean OD reading $(n=2)$ of patient's serum - mean OD of blank reading)/(mean OD reading $(n=2)$ of reference serum - mean OD of blank reading).

where the blank OD represents the value of the $H$ pylori urease uncoated control well. The intra-assay and interassay variations were less than $5 \%$, as estimated with positive and negative control sera.

DETECTION OF H PYLORI UREASE SPECIFIC ANTIBODIES IN GASTRIC JUICE

At the beginning of endoscopic diagnosis, samples of fasting gastric juice from patients with chronic gastritis were aspirated into tubes containing protease inhibitors such as EDTA $(0.65 \mathrm{mg} / \mathrm{ml})$ and aprotinin (500 KIU) to prevent further degradation. The gastric juice samples were neutralised to $\mathrm{pH} 7.4$ with $0.1 \mathrm{M}$ $\mathrm{NaOH}$ before western blotting. Anti- $H$ pylori urease specific IgG, IgA, and secretory component (SC) responses was determined by western blotting analysis. In brief, purified $H$ pylori urease complex and standard molecular masses (Sigma) were further separated by sodium dodecyl sulphate polyacrylamide gel electrophoresis (SDS-PAGE) (Gel; SPU-15S, Pagel; Atto Corporation, Tokyo, Japan) as described by Laemmli, ${ }^{25}$ and transferred onto nitrocellulose membranes by electroblotting. After blocking with $25 \%$ Block-Ace, the blots were incubated at room temperature with the sample gastric juice for 120 minutes. After washing to remove free sample antibody, the blot-sample complexes were incubated further with alkaline phosphatase conjugated goat antihuman IgA or IgG (diluted 1/300, 1/500 with 10\% Block-Ace, respectively) or peroxidase conjugated goat antihuman SC specific antibody (Nordic Immunological Laboratories, Tilburg, The Netherlands) (diluted 1/200 with 10\% Block-Ace) for 60 minutes at $37^{\circ} \mathrm{C}$. After being washed four times, the bound conjugate was detected with $200 \mu \mathrm{l}$ of substrate colour indicator.

MEASUREMENT OF H PYLORI UREASE SPECIFIC ANTIBODIES IN GASTRIC TISSUE

Three antral biopsy specimens (total weight of about $30 \mathrm{mg}$ ) were taken from the gastric mucosa of each patient listed in table 1 by endoscopic biopsy and homogenised. After adding 1 $\mathrm{ml}$ phosphate buffered saline (PBS) on ice, the samples were centrifuged at $16000 \mathrm{~g}$ for 10 minutes. The protein volume of each supernatant was assayed for total protein using a modified Lowry method ${ }^{26}$ and the mean protein concentration was approximately $0.65 \mathrm{mg} / \mathrm{ml}$. The supernatant was then adjusted to $0.5 \mathrm{mg} / \mathrm{ml}$ and harvested to measure the tissue IgA, IgG, and SC antibodies against $H$ pylori urease by ELISA as described above. The cut off points for tissue IgA (0.22), IgG (0.19), and SC (0.18) were determined using gastric tissue from $25 \mathrm{H}$ pylori uninfected disease control patients. Based on these cut off points, reference samples were made by pooling for each reference standard, five gastric samples positive for either IgA, IgG, or SC specific to $H$ pylori urease. The mean (SD) absorbance of the reference sample was $0.38(0.12)$ for $\operatorname{IgA}, 0.66(0.13)$ for IgG, and $0.32(0.10)$ for SC. Also, secretory component 


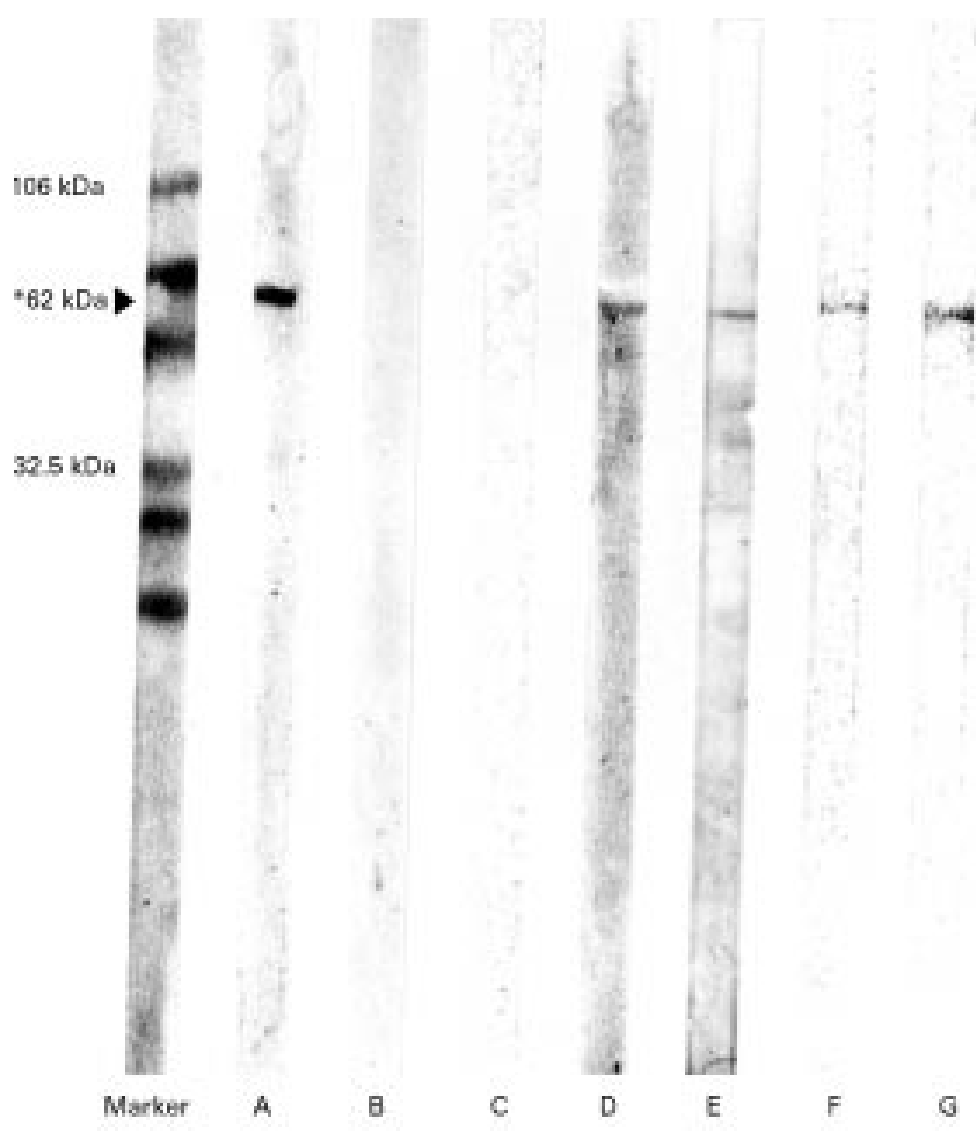

Figure 2 H pylori urease heavy chain ( $62 \mathrm{kDa}$ ) specific $\operatorname{Ig} \mathrm{G}$, $\operatorname{Ig} A$, and $S C$ responses in the gastric juice of patients. Lanes $A-C$, grade II gastritis; lanes $D-F$, grade III gastritis with haemorrhagic erosions found endoscopically; lane $G$, duodenal ulcer (active stage). Lanes $A, D$, IgG; lanes $B, E$, IgA; lanes $C, F, G$, SC.

conjugated IgA (SC IgA) in each supernatant was measured by an ELISA kit (MBL, Tokyo, Japan). ${ }^{27}$ Results were expressed quantitatively as ng SC IgA per mg wet weight of tissue.

IMMUNOHISTOCHEMICAL STUDIES

The localisation of $H$ pylori urease specific antibody producing $\mathrm{B}$ lymphocytes inside the tissue was determined by the following procedure. In brief, cryostat sections $(8 \mu \mathrm{m})$ were cut from the fresh frozen stomach specimens, air dried, and incubated with purified $H$ pylori urease $(100 \mu \mathrm{l}$ of $40 \mu \mathrm{g} / \mathrm{ml}$ ) for two hours at room temperature. After being washed with PBS and fixed in cold acetone for 10 minutes, non-specific staining was blocked with PBS containing 5\% normal goat serum and $1 \%$ bovine serum albumin. Endogenous peroxidase activity was blocked by incubating for 30 minutes in $0.6 \% \mathrm{H}_{2} \mathrm{O}_{2}$ in methanol. Tissue sections were then incubated with a mouse anti- $H$ pylori urease specific monoclonal antibody ${ }^{19}$ (1/300 dilution) for 90 minutes at room temperature. After further washing, peroxidase conjugated goat antimouse immunoglobulin (Dako, Glostrup, Denmark) (1/100 dilution) was added. The immuno- peroxidase reaction was visualised with 3,3'diaminobenzidine tetrahydrochloride (Sigma) solution containing $0.03 \% \mathrm{H}_{2} \mathrm{O}_{2}$. For counterstaining, Meyer's haematoxylin, methyl green, and/or Alcian blue at $\mathrm{pH} 2.5$ for goblet cells was used. Negative controls were made without adding the first antibody. The localisation of $H$ pylori urease was determined by the same staining procedure except for the step of involving incubation with purified $H$ pylori urease. The distribution of IgA producing lymphocytes was observed by direct staining with peroxidase conjugated rabbit antihuman IgA (Dako) (1/100 dilution).

STATISTICAL ANALYSIS

Results are expressed as the mean (SEM). Data were analysed by the Mann-Whitney U test and considered significant if any $p$ value was less than $5 \%$.

\section{Results}

H PYLORI UREASE SPECIFIC IgA AND IgG RESPONSES IN THE SERA

As indicated in fig 1 , the mean absorbance index (AI) of $H$ pylori urease specific IgA responses in the sera of patients with grade I gastritis $(0.63$ (0.31)) was significantly higher than the mean in grade II gastritis $(0.13(0.08) ; \mathrm{p}<0.05)$, the value of which was very close to the basal level of the uninfected disease controls $(0.12(0.06))$ and uninfected healthy volunteer controls $(0.10$ (0.03)), both of which should not have any IgA antibody response against $H$ pylori urease. In contrast, the mean AI of $H$ pylori urease specific IgG responses in grade II gastritis patients (1.02 $(0.25)$ ) was significantly higher than in grade I gastritis $(0.09$ (0.03); $\mathrm{p}<0.05)$, the value of which was almost equal to the basal level of the uninfected disease controls $(0.10(0.05))$ and uninfected healthy volunteer controls $(0.10$ (0.04)), both of which should not have any IgG antibody response to $H$ pylori urease. In grade III gastritis, the mean AIs of $H$ pylori urease specific IgA responses $(1.04(0.30))$ and IgG responses (1.24 (0.25)) were both significantly higher than in the uninfected disease controls or healthy volunteer controls. We then calculated the IgA:IgG ratio in each patient based on the AI values and confirmed the mean IgA:IgG ratio of each gastritis group as 7.48 (3.13), 0.13 (0.07), and 0.91 (0.52) in grades I, II, and III gastritis, respectively. Therefore, the relative ratio of IgA:IgG in each case seems to be useful in classifying the type of gastritis associated with $H$ pylori infection; in particular, a high score (greater than 4.35: mean - SD) indicated grade I gastritis and low score (less than 0.20: mean + $\mathrm{SD})$, grade II gastritis. As far as we have investigated, $H$ pylori urease specific IgM responses were mostly very weak in each group compared with control values (data not shown). Only IgA and IgG responses to purified $H$ pylori urease will therefore be measured for further study.

H PYLORI UREASE SPECIFIC IgA SECRETION FROM GASTRIC MUCOSA

As $H$ pylori urease specific IgA antibody was observed in the sera of grade III gastritis patients with mucosal damage, it is worth investigating such $H$ pylori urease specific functional IgA antibodies associated with SC in the gastric juice of these patients to determine whether local immunity to $H$ pylori urease exists in the gastric mucosa. Figure 2 shows clearly that $\operatorname{IgG}, \operatorname{IgA}$, and SC associated 

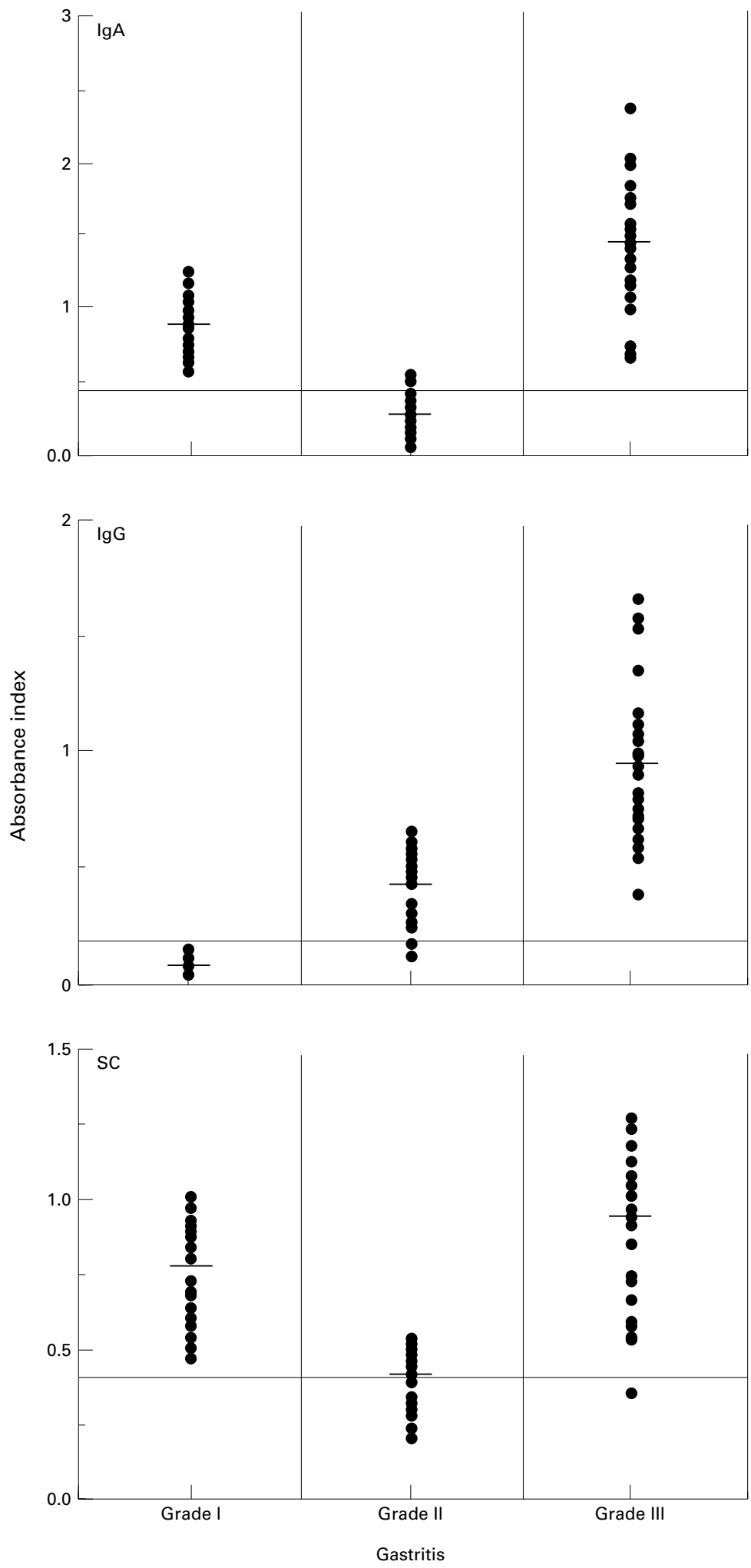

Figure 3 H pylori urease specific IgG, IgA, and SC responses in gastric tissue. Horizontal bars represent median values. Horizontal lines indicate cut off levels used in the assay.

antibody (major component should be $\operatorname{IgA}$ ) against $H$ pylori urease can be detected in the gastric juice of grade III gastritis patients with haemorrhagic erosions and severe atrophy (lanes D, E, F). Lane G shows $H$ pylori positive duodenal ulcer (active stage) as a positive control. Only an $H$ pylori urease specific IgG response was observed in grade II gastritis without mucosal change (atrophic gastritis, quiescent; lanes $\mathrm{A}, \mathrm{B}, \mathrm{C}$ ) by western blotting analysis. We have analysed by the same procedure another six cases of grade II and equal numbers of grade III gastritis with a similar pattern and confirmed these findings.

H PYLORI UREASE SPECIFIC ANTIBODY PRODUCTION IN GASTRIC TISSUE

In order to investigate the local immune response to $H$ pylori urease in gastric tissue, $H$ pylori urease specific IgA, IgG, and SC antibodies in gastric tissue of the same patients with $H$ pylori associated chronic gastritis were measured by modified ELISA methods. As fig 3 shows, a tendency similar to that found in the sera could also be observed in the tissue. The mean AI of $H$ pylori urease specific IgA and SC antibody responses in grade I gastritis $(0.84$ $(0.20), 0.77(0.16))$ was significantly higher than in grade II gastritis $(0.30(0.14), 0.41$ (0.09); $\mathrm{p}<0.05)$; the mean AI value of $H$ pylori urease specific IgG in grade II gastritis $(0.47$ (0.14)) was significantly higher than in grade I gastritis $(0.09(0.03) ; \mathrm{p}<0.05)$. In grade III gastritis, high values of the mean AI of $H$ pylori urease specific $\operatorname{IgG}(0.94(0.32)), \operatorname{IgA}(1.42$ $(0.42))$, and SC $(0.86(0.26))$ antibody responses were observed. Also, by measuring the amount of SC-IgA in the biopsy homogenate from each gastritis patient, we confirmed the existence of a comparable SC-IgA concentration: 173 (11.2) $\mathrm{ng} / \mathrm{mg}$ tissue wet weight in grade I, 178 (10.3) $\mathrm{ng} / \mathrm{mg}$ in grade II, and 188 (13.0) $\mathrm{ng} / \mathrm{mg}$ in grade III gastritis.

DISTRIBUTION OF H PYLORI UREASE SPECIFIC ANTIBODY PRODUCING B CELLS IN GASTRIC TISSUE

As $H$ pylori urease specific humoral antibodies can be observed in gastric juice and tissue as well as in sera from chronic gastritis patients, it is important to investigate the distribution of antigenic $H$ pylori urease and its specific antibody producing B cells in the gastric tissue of various patients infected with $H$ pylori. In grade III gastritis with severe atrophy and haemorrhagic erosions, $H$ pylori urease can only be seen on the surface of the mucosal membrane in association with a cluster of $H$ pylori (fig 4A); H pylori urease specific mature $\mathrm{B}$ cells were observed in most parts of the gastric mucosal tissue and within the lamina propria mucosae except lymphoid follicle(s) (fig 4B) when compared with stained control (fig 4C). Figure 4B also indicates that $H$ pylori urease specific antibody producing mature B lymphocytes do not associate with neighbouring lymphoid follicles which contain many immature B lymphocytes.

In grade II gastritis bearing intestinal metaplasia, $H$ pylori and its specific urease could be seen, even in the neighbourhood of the metaplastic epithelium in the lumen of gastric mucosa associated with goblet cells, but not in the lamina propria as indicated by arrows in the magnified box (fig 4D). In addition, small numbers of $H$ pylori urease specific antibody producing mature B lymphocytes could also be seen in this quiescent type of 

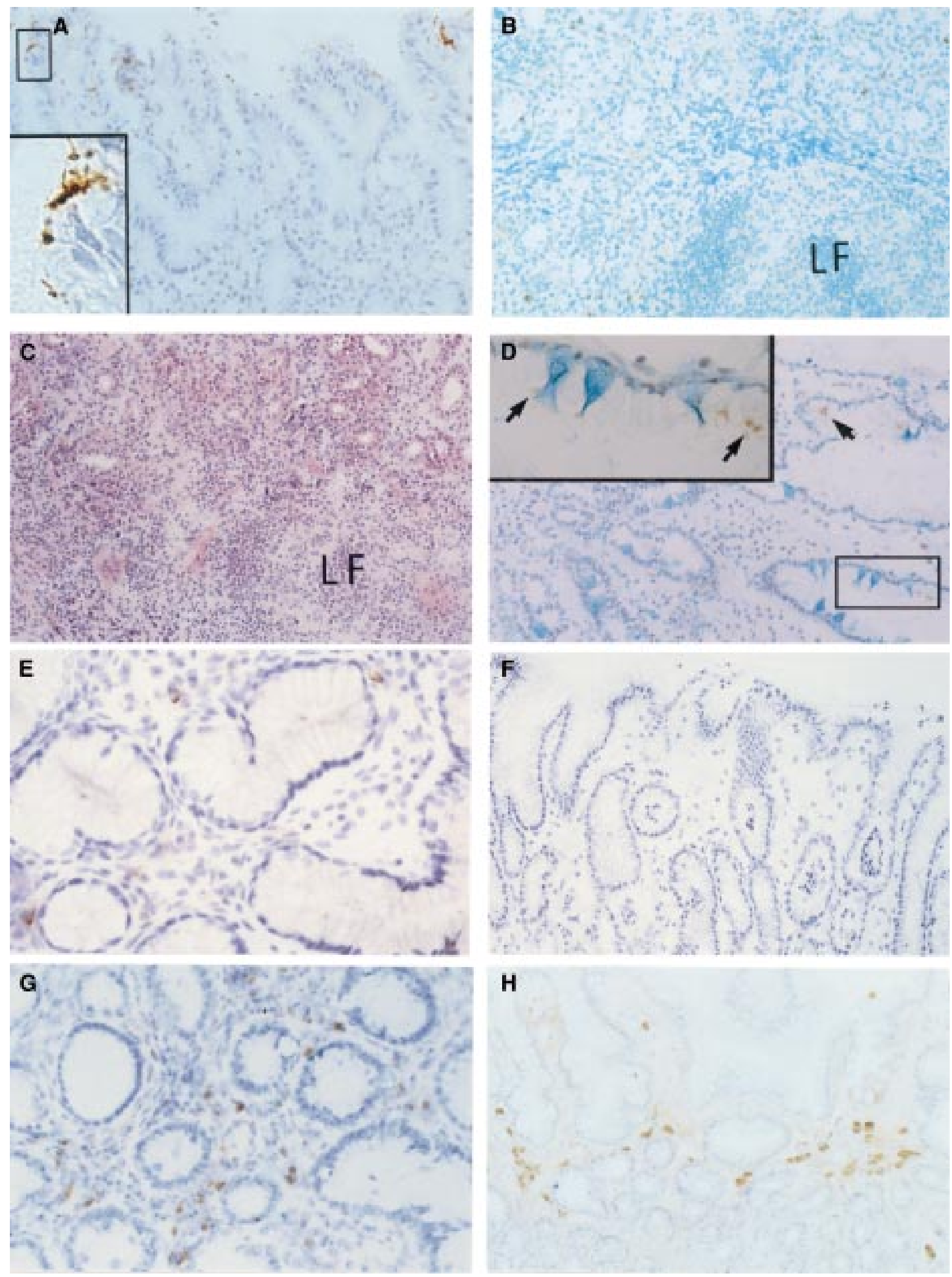

Figure 4 Immunohistochemical analysis of $H$ pylori urease specific humoral responses. (A) Localisation of $H$ pylori and $H$ pylori urease in the stomach of a patient with grade III gastritis (enzyme immunohistochemistry with monoclonal $H$ pylori urease specific antibody; Meyer's haematoxylin, original magnification $\times 160)$; a higher maginification $(\times 800)$ of the boxed area indicated in the left upper corner is shown in the left lower corner. (B) Distribution of $H$ pylori urease specific antibody producing $B$ lymphocytes (plasma cells) in the same tissue (enzyme immunohistochemistry with purified $H$ pylori urease and monoclonal $H$ pylori urease specific antibody; methyl green, original magnification $\times 150) ; L F$, lymphoid follicle. (C) Localisation of mononuclear cells in the same tissue (haematoxylin and eosin, original magnification $\times 150$ ). (D) Localisation of $H$ pylori and $H$ pylori urease indicated by arrows in the stomach of a patient with grade II gastritis (enzyme immunohistochemistry with monoclonal $H$ pylori urease specific antibody; Alcian blue, 
atrophic gastritis (fig $4 \mathrm{E}$ ). In contrast, $H$ pylori urease specific mature B lymphocytes could not be detected in the gastric mucosal tissue of grade I superficial gastritis patients (fig $4 \mathrm{~F}$ ) despite the evidence of strong production of $H$ pylori urease specific IgA antibody. Surprisingly, we could see a number of such urease specific mature B lymphocytes which may produce $H$ pylori urease specific IgA in the duodenal bulb of patients with superficial gastritis (fig 4G). Similar findings could be obtained in five cases of grade I gastritis (superficial gastritis) and it is interesting to note that all five cases also had duodenitis.

We also studied the distribution of IgA producing $\mathrm{B}$ cells in gastric tissue of the patients with grade I superficial gastritis and found such IgA positive B cells infiltrating the upper parts of the lamina propria (fig $4 \mathrm{H}$ ). Thus, some other antigen specific IgA producing B cell may be activated in the gastric tissue of grade I gastritis patients. Similar findings but with more infiltration of such specific B cells were observed in grade III gastritis patients with severe atrophy and erosions.

\section{Discussion}

The major pathological feature of $H$ pylori associated chronic gastritis is mononuclear cells, particularly plasma cells, infiltrating the lamina propria. ${ }^{28}$ Plasma cells are sparse or absent from the normal uninfected stomach. Such plasma cells emerging in association with $H$ pylori infection may produce specific antibodies in an attempt to eliminate the infection. Thus, some of the humoral immune responses against $H$ pylori components should correlate with inflammatory changes in the gastric mucosa and with the progression of gastritis.

Based on the sum of the inflammation and atrophy scores of antral biopsy specimens as defined in the Sydney system, ${ }^{12}{ }^{13}$ we showed that $H$ pylori associated chronic gastritis can be classified into three grades-I, II, and III; the relation between various types of $H$ pylori associated chronic gastritis and humoral immune responses to $H$ pylori can be graded. Under this classification scheme, we analysed IgA and IgG responses in the serum, gastric juice, and gastric tissue from patients with different grades of gastritis against purified $H$ pylori urease, which we have identified as an principal antigenic protein among various $H$ pylori components, such as heat shock protein, ${ }^{29-31}$ urease, ${ }^{5-8}$ cytotoxin, ${ }^{32}$ and cytotoxin associated gene A protein. ${ }^{33}$ We found that we can estimate the grade of the $H$ pylori associated chronic gastritis based on the IgA:IgG ratio-a high score indicates grade I (superficial) gastritis and a low score, grade II gastritis with atrophy.

Previous studies have reported that antiwhole $H$ pylori component specific IgA antibodies exist in the gastric juice, gastric tissue, and saliva. ${ }^{27}{ }^{34-36}$ Generally, secretory IgA antibody has been viewed as an immune barrier which inhibits the entrance of external foreign antigenic molecules. However, recent studies have suggested two additional functions ${ }^{37-39}$ : to neutralise intracellular microbial pathogens directly within epithelial cells; and to bind antigens in the mucosa and excrete the immune complexes (ICs) through the adjacent epithelium into the lumen to rid the body of locally produced ICs. Based on the observations, one might speculate that the former IgA, particularly in secretory form, may bind antigenic $H$ pylori urease in gastric mucosa to induce local inflammation that may elicit superficial change instead of eliminating the antigenic urease, if such ICs could not be cleared and accumulated locally. We could in fact detect $H$ pylori urease specific IgA which may form the ICs in the gastric homogenate (fig 3). Furthermore, Wyatt et al have detected coating of Campylobacter pyloridis ( $H$ pylori) by host IgA in gastritis. ${ }^{40}$ In contrast, the latter IgG, which will not combine with SC and is rapidly degraded in gastric juice, seems to relate to an internal destructive event which may correlate with atrophy because $H$ pylori shares antigenic determinants with pyloric glands ${ }^{41}$ that might elicit molecular mimicry ${ }^{42}$ and induce autoimmunity. In addition, patients with surface mucosal changes together with chronic atrophy in the gastric mucosa of grade III gastritis (atrophic gastritis, active) produce both $H$ pylori urease specific IgA and IgG responses. When we followed up some of these cases, such specific IgA responses diminished as the superficial changes disappeared, despite the continuous production of IgG against $H$ pylori urease (data not shown). Thus, as speculated above, $H$ pylori urease specific IgA responses might reflect superficial changes and its specific IgG responses may be associated with gastric atrophy. The reason for the existence of $H$ pylori urease specific IgG in the gastric juice of such patients remains to be investigated.

To investigate further the biological meanings of such local immune responses to $H$ pylori urease, we analysed the distribution of antigenic $H$ pylori urease and urease specific, antibody producing B cells in the gastric tissue of these patients. Although $H$ pylori urease could be observed only in restricted sites (fig 4A,D), $H$ pylori urease specific mature $\mathrm{B}$ cells were widely distributed in grade II and III gastritis with atrophy (fig 4B,E). In contrast, such $H$ pylori urease specific mature B lymphocytes could not be observed in the gastric tissue of grade I gastritis (fig $4 \mathrm{~F}$ ) in which IgA producing $B$ cell infiltrates were seen in the upper parts of the lamina propria (fig $4 \mathrm{H}$ ). Unexpectedly, a number of such $H$ pylori urease specific mature B lymphocytes could be observed in the duodenal bulb of the same patients with

Figure 4 (contd) -original magnification $\times 160)$; a higher magnification $(\times 640)$ of the boxed area indicated in the right lower corner is shown in the left upper corner. (E) Distribution of $H$ pylori urease specific B cells in the stomach from the same patient (enzyme immunohistochemistry with purified $H$ pylori urease and monoclonal $H$ pylori urease specific antibody; Meyer's haematoxylin, original magnification $\times 250)$. (F) Distribution of $H$ pylori urease specific plasma cells in the stomach of a patient with grade I gastritis (enzyme immunohistochemistry with purified $H$ pylori urease and monoclonal $H$ pylori urease specific antibody; Meyer's haematoxylin, original magnification $\times 125)$. (G) Detection of $H$ pylori urease specific B cells in the duodenal bulb from the same patient with grade I gastritis bearing duodenitis (enzyme immunohistochemistry with purified $H$ pylori urease and monoclonal H pylori urease specific antibody; Meyer's haematoxylin, original magnification $\times 200)$. (H) Distribution of IgA producing B cells in the stomach of the same patient (enzyme immunohistochemistry with antihuman IgA antibody, original magnification $\times 132$ ). 
grade I gastritis (fig 4G). These findings showed that most IgA producing B cells in the upper parts of the lamina propria of patients with grade I superficial gastritis were not specific for $H$ pylori urease and that some other part of the gastrointestinal tract, including the duodenum, may be a site for generating $H$ pylori urease specific IgA producing B cells that secrete urease specific IgA both in serum and gastric juice. The above results appear to reflect the fact that a number of cases of superficial gastritis are accompanied by duodenitis ${ }^{34}$ and are compatible with the speculation of Bienenstock and Befus ${ }^{43}$ that synthesis and secretion of IgA may result mostly from local plasma cells in the lamina propria of the intestine. The reason why the major $H$ pylori urease specific IgA antibody producing site appeared to shift from the gastric mucosa in grade I superficial gastritis patients remains to be studied further. Furthermore, if we reconsider the findings of Whitehead et $a l,{ }^{17}$ it would be interesting to investigate the types of infiltrating lymphocytes and their specific antigens as observed in the stomach during superficial gastritis.

Taken together, our results suggest that $H$ pylori urease specific IgG produced beneath the gastric mucosa may be associated with chronic atrophic changes within the gastric mucosa, whereas $H$ pylori urease specific IgA produced under the duodenal mucosa and circulated systemically may relate to superficial changes in the gastric mucosa. The findings shown here will be a useful tool for determining the actual stage of chronic gastritis and analysing the pathogenesis of $H$ pylori infection.

We thank Drs Yu Fukuda, Kumiko Nagata, Taku Tsukui, and We thank Drs Yu Fukuda, Kumiko Nagata, Taku Tsukui, and Graham R Leggatt for helpful suggestions and critical reading of
the manuscript, Dr Kumiko Nagata for the kind gift of $H$ pylori the manuscript, Dr Kumiko Nagata for the kind gift of $H$ pylori urease specific mouse monoclonal antibodies, and Drs Masaru Hosone, Atsushi Tatsukuchi, Kaoru Hirota, Miss Miyuki Taka-
tori, and Mr Hironori Katayama for expert technical assistance tori, and $\mathrm{Mr}$ Hironori Katayama for expert technical assistance
in immunohistochemical studies. This work was supported in in immunohistochemical studies. This work was supported in
part by grants from the Ministry of Education, Culture, and part by grants from the Ministry of Education, Culture, and
Science, from the Ministry of Health, and CREST, JST, Japan.

1 Blaser MJ. Gastric Campylobacter-like organisms, gastritis and peptic ulcer diseases. Gastroenterology 1987;93:371-83. 2 Dixon MF. Helicobacter pylori and peptic ulceration: 125-30.

3 Berstad AE, Brandtzaeg P, Stave R, et al. Epithelium related deposition of activated complement in Helicobacter pylori associated gastritis. Gut 1997;40:196-203.

4 Karttunen R, Karttunen T, Ekre H-P T, et al. Interferon gamma and interleukin 4 secreting cells in the gastric antrum in Helicobacter pylori positive and negative gastriantrum in Helicobacter
tis. Gut $1995 ; 36: 341-5$.

5 Mai UEH, Perez-Perez GI, Wahl LM, et al. Soluble surface proteins from Helicobacter pylori activate monocytes/ macrophages by lipopolysaccharide-independent mechanism F Clin Invest 1991;87:894-900.

6 Futagami S, Takahashi H, Norose Y, et al. Analysis of immune response to Helicobacter pylori: identification of the protein recognized by anti-Helicobacter pylori antibodies from sera of patients with gastroduodenal diseases. $\exists_{p n}$ f Gastroenterol 1994;91:2202-13.

7 Newell DG. Identification of the outer membrane proteins of Campylobacter pyloridis and antigenic cross-reactivity
between C. pyloridis and C. jejuni. f Gen Microbiol 1987;133:163-70.

8 Dent JC, McNulty CAM, Uff JS, et al. Campylobacter pylori urease: a new serological test. Lancet 1988;i:1002.

9 Czinn S, Carr H, Sheffler L, et al. Serum IgG antibody to the outer membrane proteins of Campylobacter pylori in the outer membrane proteins of Campylobacter pylori in
children with gastroduodenal disease. F Infect Dis 1989;159: 586-9.

10 Eaton KA, Brooks CL, Morgan DR, et al. Essential role of urease in pathogenesis of gastritis induced by Helicobacter pylori in gnotobiotic piglets. Infect Immun 1991;59:2470-5

11 Eaton KA, Krakowka S. Effect of gastric $\mathrm{pH}$ on ureasedependent colonization of gnotobiotic piglets by Helicobacter pylori. Infect Immun 1994;62:3604-7.
12 Misiewicz JJ, Tytgat G, Goodwin CS, et al. The Sydney system: a new classification of gastritis. In: Working party reports of the 9th World Congress of Gastroenterology. Melbourne: Blackwell Scientific, 1989:1-10.

13 Price AB. The Sydney system: histological division. $f$ Gastroenterol Hepatol 1991;6:209-22.

14 Marshall BJ, Warren JR, Francis GJ, et al. Rapid urease test in the management of Campylobacter pyloridis-associated gastritis. Am f Gastroenterol 1987;82:200-10.

15 Atherton JC, Spiller RC. The urea breath test for Helicobacter pylori. Gut 1994;35:723-5.

16 Gray SF, Wyatt JI, Rathbone BJ. Simplified techniques for identifying Campylobacter pyloridis. $\mathcal{F}$ Clin Pathol 1986;39: 1279-80.

17 Whitehead R, Truelove SC, Gear MWL. The histological diagnosis of chronic gastritis in fibreoptic gastroscope biopsy specimens. F Clin Pathol 1972;25:1-11.

18 Clayton CL, Pallen MJ, Kleanthous H, et al. Nucleotide sequence of two genes from Helicobacter pylori encoding sequence of two genes from Helicobacter pylori enco
for urease subunits. Nucleic Acids Res 1989;18:362.

19 Nagata K, Mizuta T, Tonokatu Y, et al. Monoclonal antibodies against the native urease of Helicobacter pylori: antibodies against the native urease of Helicobacter pylori: bynergistic inhibition of urease activity by monoclon

20 Parsonnet J, Friedman GD, Orentreich N, et al. Risk for gastric cancer in people with CagA positive or CagA negative Helicobacter pylori infection. Gut 1997;40:297-301.

21 Kreuning J, Lindeman J, Biemond I, et al. Relation between IgG and IgA antibody titers against Helicobacter pylori in serum and severity of gastritis in asymptomatic subjects. $\mathcal{F}$ Clin Pathol 1994;47:227-31.

22 Pena AS, Endtz HPh, Offerhaus GJA, et al. Value of serology (ELISA and immunoblotting) for the diagnosis of Campylobacter pylori infection. Digestion 1989;44:131-41.

23 Kuipers EJ, Pena AS, van Kamp G, et al. Seroconversion for Helicobacter pylori. Lancet 1993;342:328-31.

24 Veenendaal RA, Götz JM, Schroijen V, et al. Diagnosis of Helicobacter pylori infection by specific gastric mucosal IgA and IgG pylori antibodies. F Clin Pathol 1995;48:9903.

25 Laemmli UK. Cleavage of structural proteins during the assembly of the head of bacteriophage T4. Nature 1970;227:680-5.

26 Peterson GL. A simplification of the protein assay method of Lowry et al which is more generally applicable. Anal Biochem 1977;83:346-56.

27 Matsukura N, Onda M, Tokunaga A, et al. Mucosal IgA antibody against Helicobacter pylori in chronic gastritis and intestinal metaplasia detected by the tes-tape method in resection specimens after gastrectomy for gastric cancer. Cancer 1995;75:1472-7.

28 Chen XG, Correa P, Offerhaus J, et al. Ultrastructure of the gastric mucosa harboring Campylobacter-like organisms. Am $\mathcal{F}$ Clin Pathol 1986;86:575-82.

29 Perez-Perez GI, Brown WR, Cover TL, et al. Correlation between serological and mucosal inflammatory responses to Helicobacter pylori. Clin Diagn Lab Immunol 1994;1: 325-9.

30 Dunn BE, Roop II RM, Sung C-C, et al. Identification and purification of a cpn60 heat shock protein homolog from Helicobacter pylori. Infect Immun 1992;60:1946-5

31 Evans DJ Jr, Evans DG, Engstrand L, et al. Ureaseassociated heat shock protein of Helicobacter pylori. Infect Immun 1992;60:2125-7.

32 Leunk RD, Ferguson MA, Morgan DR, et al. Antibody to cytotoxin in infection by Helicobacter pylori. $\mathcal{F}$ Clin Microbiol 1990;28:1181-4

33 Covacci A, Censini S, Bugnoli $\mathrm{M}$, et al. Molecular characterization of the $128-\mathrm{kDa}$ immunodominant antigen of Helicobacter pylori associated with cytotoxicity and duodenal ulcer. Proc Natl Acad Sci USA 1993;90:5791-5.

34 Crabtree JE, Shallcross TM, Wyatt JI, et al. Mucosal humoral immune response to Helicobacter pylori in patients with duodenitis. Dig Dis Sci 1991;36:1266-73.

35 Patel P, Mendall MA, Khulusi S, et al. Salivary antibodies to Helicobacter pylori: screening dyspeptic patients before endoscopy. Lancet 1994;344:511-12.

36 Crabtree JE, Figura N, Taylor JD, et al. Expression of 120 kilodalton protein and cytotoxicity in Helicobacter pylori. $f$ Clin Pathol 1992;45:733-4.

37 Crabtree JE, Shallcross TM, Heatley RV, et al. Mucosal tumour necrosis factor $\alpha$ and interleukin- 6 in patients with Helicobacter pylori-associated gastritis. Gut 1991;32: 1473-7.

38 Kaetzel CS, Robinson JK, Chintalacharuvu KR, et al. The polymeric immunoglobulin receptor (secretory component) mediates transport of immune complexes across epithelial cells: a local defense function for IgA. Proc Natl Acad Sci USA 1991;88:8796-800.

39 Mazanec MB, Nedrud JG, Kaetzel CS, et al. A three-tiered view of the role of $\mathrm{IgA}$ in mucosal defense. Immunol Today 1993; 14:430-5.

40 Wyatt JI, Rathbone BJ, Heatley RV. Local immune response to gastric Campylobacter in non-ulcer dyspepsia. $\mathcal{f}$ Clin Pathol 1986;39:863-70.

41 Negrini R, Lisato L, Cavazzini L, et al. Monoclonal antibodies for specific immunoperoxidase detection of Campylobacter pylori. Gastroenterology 1989;96:414-20.

42 Baum H, Davies H, Peakman M. Molecular mimicry in the MHC: hidden clues to autoimmunity? Immunol Today 1996;64:64-70

43 Bienenstock J, Befus AD. Some thoughts on the biologic role of immunoglobulin A. Gastroenterology 1983;84:17885 